\title{
Juan A. Amat \\ Should females of migratory dabbling ducks switch mates between wintering and breeding sites?
}

\begin{abstract}
Pairing of northern hemisphere dabbling ducks normally occurs in wintering sites. Mate choice occurs when some individuals congregate in courtship parties, in which females mainly choose mates according to male behavioural dominance. The sex ratio of some species is more malebiased at northern than at southern wintering sites, and the age ratio is adult-biased in northern areas. A possible mechanism responsible for this spatial segregation of sex and age classes is behavioural dominance, with males usually dominating females and adults dominating yearlings. Due to this latitudinal segregation of sexes during winter, presumably more males would remain unpaired in northern sites utilized by the more dominant birds than in southern sites utilized by the less-dominant birds, and this is paradoxical. I argue that some females having wintered and paired in southern sites may switch mates at stopover sites during northward migration. This hypothesis provides an explanation as to why, in spite of females being paired when initiating northward migration, some species show an increase in courtship activity during spring at stopover sites, as in common teals (Anas crecca) in southern Spain. In contrast, populations that do not migrate, e.g. mallards (A. platyrhynchos) in southern Spain, do not exhibit an increase in courtship activity during spring.
\end{abstract}

Key words Anas - Courtship rates · Mate switching - Pair bonds $\cdot$ Pairing strategies

\section{Introduction}

In migratory dabbling ducks, mate choice occurs when individuals participate in courtship parties, in which several

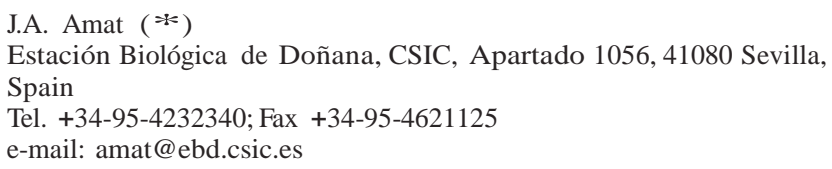

males display usually to a single female [defined as "communal courtships" by Cramp and Simmons (1977) and "social courtships" by McKinney (1986)]. Wishart (1983), Brodsky et al. (1988) and Hepp (1989) showed that American wigeon (Anas americana), mallard (A. platyrhynchos) and black duck (A. rubripes) females mainly chose mates according to male behavioural dominance (but see Bossema and Roemers 1985; Sorenson and Derrickson 1994). Pair formation generally occurs months before breeding (McKinney 1986) and females benefit from early pairing because they feed more efficiently, since their mates defend them from harassment by other males (Ashcroft 1976; Afton and Sayler 1982; Paulus 1983; McKinney 1986; Rohwer and Anderson 1988; Guillemain et al. 2003; but see Nakamura and Atsumi 2000).

The sex ratio of most migratory dabbling duck species is more male-biased at northern than at southern wintering sites; and the age ratio is also adult-biased in northern areas (Bellrose et al. 1961; Campredon 1983; Van Impe 1984). One possible mechanism for this spatial segregation of sex and age classes is behavioural dominance (Gauthreaux 1978), with adults dominating yearlings, paired ducks dominating unpaired ones and males usually dominating females (Paulus 1983; Hepp and Hair 1984; Campredon 1986; but see Thompson and Baldassarre 1992). Due to the latitudinal segregation of the sexes during winter, males wintering in northern sites, where the sex ratio is more male biased, would be at a mating disadvantage with respect to the presumably less dominant, younger males wintering in southern areas, where the sex ratio is not so male-biased as in northern areas and the mating opportunities may be better. That is, presumably more males would remain unpaired in northern sites utilized by the more dominant birds than in southern sites utilized by the less dominant birds, and this is paradoxical.

A phenomenon whose importance on the pairing strategies of migratory dabbling ducks has not been previously addressed is that male-biased sex ratios along migration routes, coupled with a likely higher dominance status of males having spent the winter in northern sites, may make it advantageous for females having wintered and paired in 
southern sites to switch mates at stopover sites during northward migration.

Although dabbling ducks generally pair long before breeding (McKinney 1986), the bonds of some pairs may not be firmly established and females may test several males before a strong bond is established. Some females have been observed to switch mates on the wintering grounds (McKinney and Stolen 1982; Wishart 1983; Paulus 1988; Pattenden and Boag 1989). Given this sequential matesampling strategy of females, mate-switching could take place along migratory routes due to the likely presence of unpaired and more dominant males at northern sites. Therefore, I predict that, coinciding with the passage of migratory birds at stopover sites, courtship activity should increase in migratory species. I also predict that populations that do not perform long-range migrations should not exhibit an increase in the frequency of occurrence of courtship parties during late winter/early spring. To test these predictions, I recorded courtship rates of mallard and common teal (A. crecca) in southern Spain, where the former species is non-migratory (Sociedad Española de Ornitología 1985), but the latter is migratory (Asensio and Carrascal 1992). Therefore, in southern Spain, the courtship rate of common teals, but not that of mallards, should peak in late winter/spring, coinciding with the migratory passages of teals that spent the winter in northwestern Africa.

\section{Materials and methods}

To quantify courtship rates, I scan-sampled (see Altmann 1974) flocks of mallards (October-April) and common teals (December-March) for the occurrence of courtship parties. Courtship parties of mallards and teals involved groups of birds, on average 5-7 males and 1-2 females (personal observation). The number of males participating in these parties could be easily accounted for, because males congregated very closely around the female(s) while performing displays and females performed nod-swimming and incited (McKinney 1986). The observations were conducted during 1984-1989, using a spotting scope, in wetlands that are protected (a national park, three nature reserves) and in which hunting is forbidden. I recorded the number of courtship parties during observation sessions lasting $1.8 \pm 2.5 \mathrm{~h} \quad(\mathrm{SD} ; n=49)$ for common teal and $1.9 \pm 2.2 \mathrm{~h}(n=40)$ for mallard. Every courtship party was recorded only once. The possibility of pseudoreplication was very low because the flocks were scanned only once when the number of birds in wetlands was low $(<50)$; and when the number of birds was high the probability of recording the same individual more than once should have been very small. The observation sessions within months were distributed temporally to ensure coverage from sunrise to sunset. Courtship rate was calculated as the number of courtship parties recorded per hour of observation and expressed relative to 100 individuals. Monthly differences in courtship rates were tested with analyses of variance on log-transformed data.

\section{Results}

The mean numbers of mallards and common teals in wetlands where the observations were conducted were $137 \pm 131(n=40)$ and $278 \pm 264(n=49)$, respectively. The numbers of individuals of both species in such wetlands were higher in autumn than in winter/spring (Fig. 1).

Courtship parties of mallard were observed between October and April, and in southern Spain its occurrence did not exhibit a peak during spring, as predicted for a nonmigratory population. In contrast, the courtship rate of mallards decreased from February onwards (Fig. 2; $F_{6,33}=2.44$, $P=0.046$; log-transformed data) coinciding with the onset of breeding (Amat 1982).
Fig. 1. Mean numbers $( \pm 1 \mathrm{SE})$ of mallards and common teals in wetlands of southern Spain where observations on courtship parties were recorded. Sample sizes are indicated beside datapoints
Fig. 2. Courtship rates (mean \pm 1 $\mathrm{SE}$, log-transformed) of mallards and common teals in southern Spain during October-April.

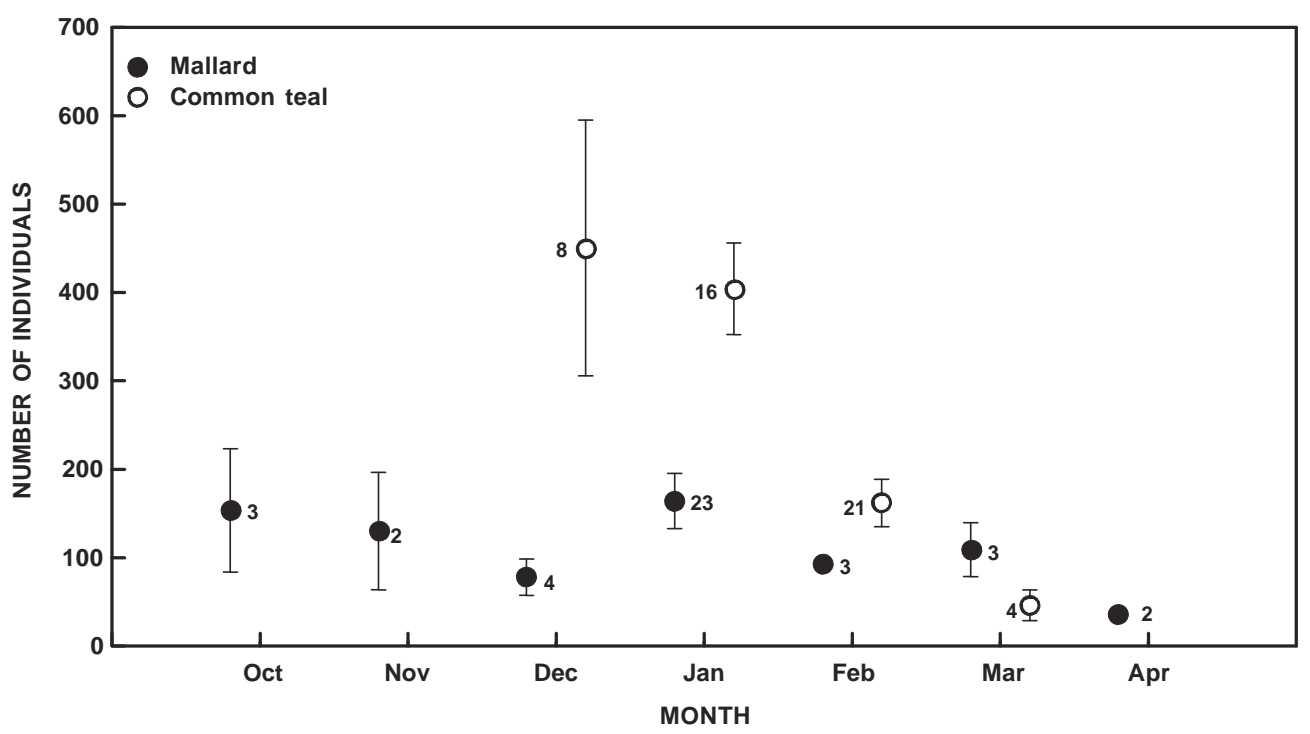

C hip rates were

o calculated as the

ur number of

ts $\quad$ courtship parties recorded per hour of observation during each recording session and expressed relative to 100 individuals. The numbers of observation sessions per month are indicated beside datapoints 


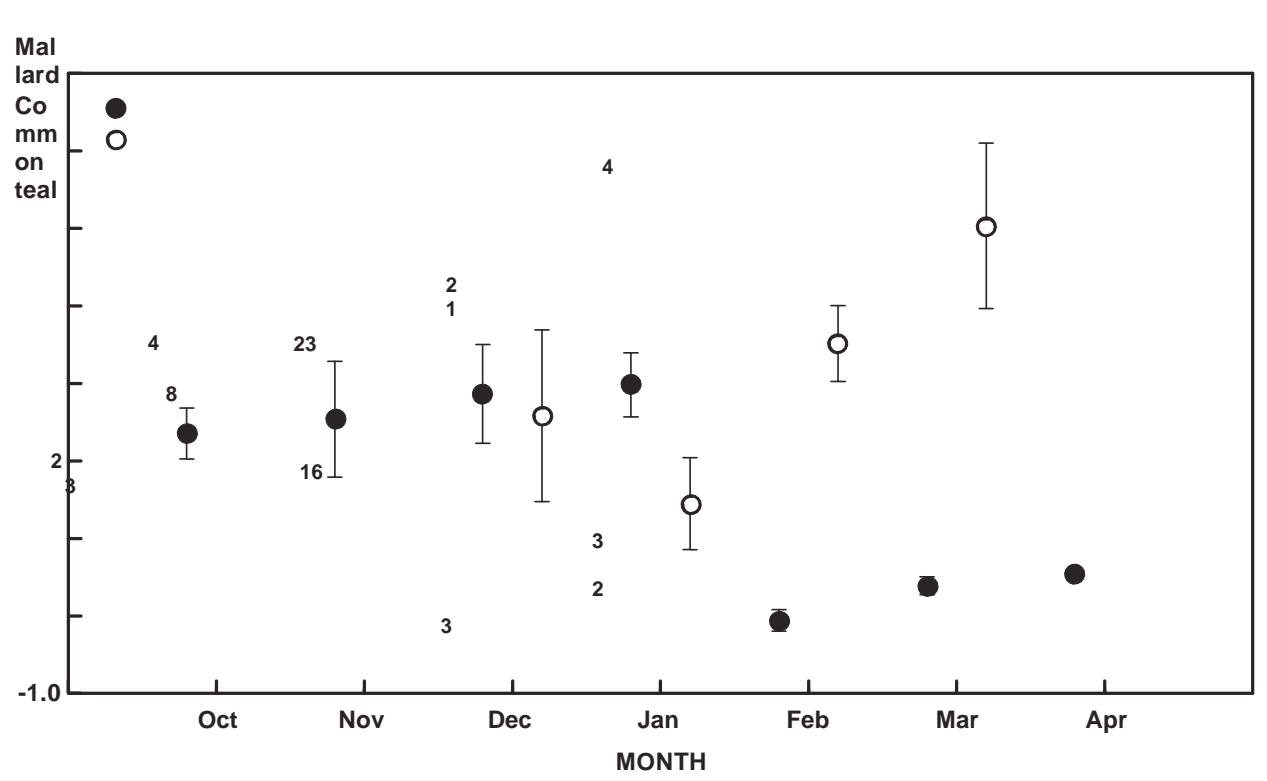

Courtship parties of common teals were mainly observed between December and March, and little courtship activity was recorded outside that period, in spite of the regular presence of the common teal in southern Spain during October-March (Amat and García 1979). The rate of courtships of common teals in southern Spain decreased from December to January, but increased in February and March (Fig. 2; $F_{3,45}=3.05, P=0.038$; log-transformed data) despite decreasing population size (Amat and García 1979).

\section{Discussion}

The pattern of occurrence of courtship rates of common teals and mallards in southern Spain supports the hypothesis that, in migratory populations, females may switch mates at stopover sites during northward migration. In southern Spain, where mallards are non-migratory, there was no increase in the courtship rates of this species during late winter/early spring, contrary to what was observed for migratory common teals. However, the courtship rates of migratory populations of mallards, as well as those of gadwalls (A. strepera) and pintails (A. acuta), have been observed to peak in autumn or early winter and again in spring during migration periods (Cramp and Simmons 1977). In the case of gadwalls, Palmer (1976) indicated that "there is much pairing activity during spring migration", despite the fact that nearly all females may be paired in late winter before they initiate migration.

Although the increase in courtship rates at stopover sites during migration is consistent with the hypothesis of mateswitching by females along migration routes, an alternative hypothesis could also explain the increase in courtship rates recorded in migratory populations at stopover sites. The function of courtship parties might be related more to male-male competition and establishing dominance ranking between males than to mate choice by females. Because resident populations may have a more stable social struc- ture than migratory populations, males would have less need to display in resident populations, where dominance status was already established, than in migratory populations, for which an influx of new individuals would create some instability and could lead to an increase in courtship activity to re-establish dominance positions. This hypothesis suggests that the establishment of dominance ranking should be for the acquisition of resources other than mates. However, this hypothesis does not explain why, in resident populations, courtship parties are also recorded once dominance positions have been established (Bossema and Roemers 1985). Furthermore, the duration of the stays of migratory ducks at stopover sites may be rather short (e.g. 5 days for garganey, A. querquedula; Guillemain et al. 2004), and the turnover of individuals may be high, so that under these circumstances it seems unlikely that the function of courting in parties at stopover sites would be to establish dominance positions. Also, the fact that the aim of the stays of migratory individuals at stopover sites is more for resting than refuelling (Guillemain et al. 2004) suggests that the function of courting in parties at such sites is not related to the establishment of dominance ranks for the acquisition of resources. In fact, displays directed by males at rival males when courting in parties function only in competition for mates, mate defence or in appeasement of other males (see McKinney et al. 1990).

From a female's perspective, it may be very important to reach the breeding grounds mated to a male able to defend her from forced copulation attempts by other males (Wishart 1983; Davis 2002), and in fact, in polygynous species, dominant males could successfully defend more than one female (Sorenson 1992). Interestingly, Afton (1985) suggested and Sorenson (1992) showed that the ability of males to guard their mates during the breeding season is an important determinant of female breeding success.

The possibility that mate-switching by female dabbling ducks may occur along migration routes adds complexity to waterfowl mating systems, in particular to sexual selection and conflict in this group. 
Acknowledgements The data presented in this paper were gathered during field studies supported by CICYT project PR84-0243-C047-01. Manuscript preparation was funded by the Dirección General de Investigación with EU-ERDF support (research grant BOS200204695). I am very grateful to A. Afton, G. Hepp, J. Lovvorn, two anonymous referees and the editors for their comments on earlier versions of this paper.

\section{References}

Afton AD (1985) Forced copulation as a reproductive strategy of male lesser scaup: a field test of some predictions. Behaviour 92:146-167

Afton AD, Sayler RD (1982) Social courtship and pairbonding of common goldeneyes, Bucephala clangula, wintering in Minnesota. Can Field Nat 96:295-300

Altmann J (1974) Observational study of behavior: sampling methods. Behaviour 49:227-267

Amat JA (1982) The nesting biology of ducks in the Marismas of the Guadalquivir, south-western Spain. Wildfowl 33:94-104

Amat JA, García L (1979) Distribución y fluctuaciones mensuales de aves acuáticas en Andalucía occidental. Invierno 1977/78. Donana Acta Vert 6:77-90

Asensio B, Carrascal LM (1992) Migration of common teal (Anas crecca) wintering in the Iberian Peninsula. Folia Zool 41:45-53

Ashcroft RE (1976) A function of the pairbond in the common eider. Wildfowl 27:101-105

Bellrose FC, Scott TG, Hawkins AS, Low JB (1961) Sex ratios and age ratios in North American ducks. Ill Nat Hist Surv Bull 27:391-474

Bossema I, Roemers E (1985) Mating strategy, including mate choice, in mallards. Ardea 73:147-157

Brodsky LM, Ankney CD, Dennis DG (1988) The influence of male dominance on social interactions in black ducks and mallards. Anim Behav 36:1371-1378

Campredon P (1983) Sexe et âge ratios chez le canard siffleur Anas penelope L. en période hivernale en Europe de l'Ouest. Rev Ecol 37:117-128

Campredon P (1986) Agressivité intraspécifique et hiérarchies d'accès aux ressources chez le canard siffleur, Anas penelope, en période hivernale. Gerfaut 76:13-18

Cramp S, Simmons KEL (eds) (1977) The birds of the western Palearctic, vol. 1: ostrich to ducks. Oxford University Press, Oxford

Davis ES (2002) Female choice and the benefits of mate guarding by male mallards. Anim Behav 64:619-628

Gauthreaux SA Jr (1978) The ecological significance of behavioral dominance. In: Bateson PPG, Klopfer P (eds) Perspectives in ethology, vol. 3: social behavior. Plenum, New York, pp 17-54

Guillemain M, Caldow RWG, Hodder KH, Goss-Custard JD (2003) Increased vigilance of paired males in sexually dimorphic species: distinguishing between alternative explanations in wintering Eurasian wigeon. Behav Ecol 14:724-729
Guillemain M, Fritz H, Klaassen M, Johnson AR, Hafner H (2004) Fuelling rates of garganey (Anas querquedula) staging in the Camargue, southern France, during spring migration. J Ornithol 145:152-158

Hepp GR (1989) Benefits, costs, and determinants of dominance in American black ducks. Behaviour 109:222-234

Hepp GR, Hair JD (1984) Dominance in wintering waterfowl (Anatini): effects on distribution of sexes. Condor 86:251-257

McKinney F (1986) Ecological factors influencing the social systems of migratory dabbling ducks. In: Rubenstein DI, Wrangham RW (eds) Ecological aspects of social evolution. Princeton University Press, Princeton, pp 153-171

McKinney F, Stolen P (1982) Extra-pair-bond courtship and forced copulation among captive green-winged teal (Anas crecca carolinensis). Anim Behav 30:461-474

McKinney F, Sorenson LG, Hart M (1990) Multiple functions of courtship displays in dabbling ducks. Auk 107:188-191

Nakamura M, Atsumi T (2000) Adaptive significance of winter pair bond in male pintail, Anas acuta. J Ethol 18:127-131

Palmer RS (ed) (1976) Handbook of North American birds, vol. 2: waterfowl (first part). Yale University Press, New Haven

Pattenden RK, Boag DA (1989) Effects of body mass on courtship, pairing, and reproduction in captive mallards. Can J Zool 67:495-501

Paulus SL (1983) Dominance relations, resource use, and pairing chronology of gadwalls in winter. Auk 100:947-952

Paulus SL (1988) Social behavior and pairing chronology of mottle ducks during autumn and winter in Louisiana. In: Weller MW (ed) Waterfowl in winter. University of Minnesota, Minneapolis, pp 5970

Rohwer FC, Anderson MG (1988) Female-biased philopatry, monogamy, and the timing of pair formation in migratory waterfowl. In: Johnston RF (ed) Current ornithology, vol. 5. Plenum, New York, pp 187-221

Sociedad Española de Ornitología (1985) Estudio sobre la biología migratoria del Orden Anseriformes (Aves) en España. Instituto Nacional para la Conservación de la Naturaleza, Madrid

Sorenson LG (1992) Variable mating system of a sedentary tropical duck: the white-cheeked pintail (Anas bahamensis bahamensis). Auk 109:277-292

Sorenson LG, Derrickson SR (1994) Sexual selection in the northern pintail (Anas acuta): the importance of female choice versus malemale competition in the evolution of sexually-selected traits. Behav Ecol Sociobiol 35:389-400

Thompson JD, Baldassarre GA (1992) Dominance relationships of dabbling ducks wintering in Yucatan, Mexico. Wilson Bull 104:529536

Van Impe J (1984) Sex-ratio’s van Anatini in enkele overwinteringsgebieden van Noord-België en Zuidwest-Nederland. Gerfaut 74:189204

Wishart RA (1983) Pairing chronology and mate selection in the American wigeon (Anas americana). Can J Zool 61:1733-1743 